\title{
Effects of Two Different Self-Adapted Occlusal Splints on Electromyographic and Force Parameters During Elbow Flexors IsOMETRIC Contraction
}

\author{
Eloisa Limonta, ${ }^{1}$ Chiara Arienti, ${ }^{1,2}$ Susanna Rampichini, ${ }^{1}$ Massimo Venturelli, ${ }^{1}$ \\ Emiliano Cè, ${ }^{1}$ Arsenio Veicsteinas, ${ }^{1,2}$ and Fabio Esposito ${ }^{1,2}$ \\ ${ }^{1}$ Department of Biomedical Sciences for Health, University of Milan, Milan, Italy; and ${ }^{2}$ Center of Sport Medicine, IRCCS Don \\ Gnocchi Foundation, Milan, Italy
}

\begin{abstract}
Limonta, E, Arienti, C, Rampichini, S, Venturelli, M, Cè, E, Veicsteinas, A, and Esposito, F. Effects of two different selfadapted occlusal splints on electromyographic and force parameters during elbow flexors isometric contraction. J Strength Cond Res 32(1): 230-236, 2018-The study was aimed at determining the acute effects of 2 types of occlusal splints on maximum isometric strength and fatigue of the elbow flexors muscles. The hypothesis was that splint-induced masticatory muscle repositioning might improve primary muscles recruitment by stretching masticatory muscles especially with the thicker splint. On 9 physically active volunteers with no temporomandibular joint and masticatory muscles disorders, we assessed maximum voluntary contraction (MVC) of the elbow flexors with diurnal $\left(\mathrm{OS}_{\mathrm{D}}, 1-\mathrm{mm}\right.$ thick) and sport $\left(\mathrm{OS}_{\mathrm{SP}}\right.$, 3-mm thick) splints, and without splint (control, Ctrl). On different days, participants performed 60 seconds of isometric contraction at $100 \% \mathrm{MVC}\left(100 \%_{60 \mathrm{~s}}\right)$ and $80 \% \mathrm{MVC}$ contraction until exhaustion $(80 \%$ exh $)$ under $\mathrm{OS}_{\mathrm{D}}, \mathrm{OS}_{\mathrm{SP}}$, and $\mathrm{Ctrl}$ in random order. Time of force output within target (t-target), force distance from target $(\Delta F)$, and force coefficient of variation were calculated. Percentage of force decay $\left(\Delta_{\mathrm{Fi}-\mathrm{Fe}}\right)$ was determined during $100 \%_{60}$ s. From the electromyographic (EMG) signal, root mean square (EMG RMS) and mean frequency (EMG MF) were determined. Neuromuscular efficiency (NE) was calculated as the ratio between force and EMG RMS. MVC contraction and NE were significantly higher in $\mathrm{OS}_{\mathrm{SP}}$ and $\mathrm{OS}_{\mathrm{D}}$ than in Ctrl. During MVC, EMG MF was significantly lower in both splint conditions, and EMG RMS showed a nonstatistical tendency to lower values under both splint conditions. During $80 \%_{\text {exh }}$, t-target was longer in $\mathrm{OS}_{\mathrm{D}}$ and $\mathrm{OS}_{\mathrm{SP}}$
\end{abstract}

Address correspondence to Fabio Esposito, fabio.esposito@unimi.it.

$32(1) / 230-236$

Journal of Strength and Conditioning Research

(c) 2017 National Strength and Conditioning Association

\section{Journal of Strength and Conditioning Research}

$\left(+7.8 \%\right.$ and $+5.2 \%$, respectively) than in Ctrl. $\Delta_{\mathrm{Fi}-\mathrm{Fe}}$ was lower in $\mathrm{OS}_{\mathrm{SP}}$ than in $\mathrm{Ctrl}$ and $\mathrm{OS}_{\mathrm{D}}$. These results support the hypothesis of a NE improvement of the elbow flexors possibly induced by acute, splint-induced masticatory muscles repositioning.

KEY WoRDS strength, endurance, mouthguard, fatigue, EMG

\section{INTRODUCTION}

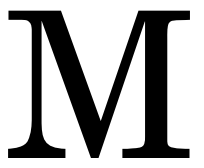

outhguards are considered to be an effective and cost-efficient device recommended by the American Dental Association in various sports to decrease the risk of orofacial injuries (30). Although face and mouth injuries were estimated to affect $50 \%$ of the players, this incidence decreased markedly to $1.4 \%$ as a result of the mandatory use of mouthguards $(27,30)$. Although mouthguards have been shown to protect against orofacial injuries, many players do not wear them during training sessions and competitions because of the discomfort, difficulty in verbal communication, and breathing, thus interfering with athletic performance (14). For this reason, the effects of mouth appliances on physical performance translated into formal scientific research as early as the 1960s $(18,30)$, uncovering positive effects of oral appliances, which were mainly designed to properly align the temporomandibular joint (TMJ), on maximum strength (28), power (1), endurance (13), expiratory ventilation (12), and posture (2). This improvement in performance needed to be accompanied by structural changes of the devices, with a decrease in vertical amplitude and thickness, to make it more comfortable during sport activities $(20,21)$.

Mainly 2 types of oral device (oral splint, OS) have been designed to optimize the contact and distribution of pressure between the upper and lower dental arch (26) and possibly to induce optimal TMJ placement $(7,10)$ : (a) self-adapted, over the counter "boil-and-bite" devices and (b) custommade splints, manufactured on models cast from individual dental impressions. The latter show optimal comfort and 
wearability $(9,31)$ and are the best protection against orofacial injuries $(4,24)$. However, they are more expensive, and consequently many recreational athletes tend to prefer the first type. Acute OS usage may determine a distancing of the dental arches and create a mandibular stability with an increase in vertical distance between superior and inferior arch (29,32). As described previously, isometric strength was found to increase significantly with the elevation of vertical dimension (5). Indeed, masticatory muscles repositioning in the vertical direction has been shown to induce beneficial ergogenic effects in healthy individuals (23). However, the mechanisms underlying OS effects on physical performance are still a matter of debate.

Most of the scientific literature examining the effects of splint-induced jaw repositioning on physical performance focused mainly on dynamic muscular strength $(1,6,15,17,34)$. However, the effects of splint usage, either customized or self-adapted, have been so far poorly investigated on isometric muscle activity.

On these bases, the aim of this study was to determine the effects of 2 different "boil-and-bite" (self-adapted) devices on maximum isometric strength and response to fatigue in recreational athletes. In particular, the effects of diurnal $\left(\mathrm{OS}_{\mathrm{D}}\right.$, 1-mm thick) or sport splint ( $\mathrm{OS}_{\mathrm{SP}}, 3-\mathrm{mm}$ thick) usage were compared with a condition without any device (control, Ctrl).

\section{Methods}

\section{Experimental Approach to the Problem}

The repeated-measures study design aimed at assessing isometric strength performance with and without the use of 2 kinds of over the counter, boil-and-bite devices. The study was conducted under 3 experimental conditions: with diurnal $\left(\mathrm{OS}_{\mathrm{D}}, 1-\mathrm{mm}\right.$ thick) or sport splint $\left(\mathrm{OS}_{\mathrm{SP}}, 3-\mathrm{mm}\right.$ thick) (Dr. Brux, Montefarmaco, Italy), and without any device (control, Ctrl). The pictures of the 2 models of splint are shown in Figure 1. Participants reported to the laboratory 5 times. During the first visit, participants were familiarized with the experimental procedures and the instruments used to reduce the variability of the measurements as much as possible. In the second visit, participants performed 3 trials of maximum voluntary contraction (MVC) under each experimental condition for reliability purpose. In the next 3 sessions, after reassessing MVC, participants were asked to perform 2 different isometric tasks, separated by a resting period of at least 2 hours: 1 isometric contraction at $100 \% \mathrm{MVC}$ for 60 seconds $\left(100 \%_{60 \mathrm{~s}}\right)$ and $80 \%$ MVC isometric contraction until exhaustion $\left(80 \%_{\text {exh }}\right)$ under $\mathrm{OS}_{\mathrm{D}}, \mathrm{OS}_{\mathrm{SP}}$, and Ctrl condition, respectively, in random order. The last 3 sessions were randomly performed. Subjects were always supervised by a qualified operator during tests. The correct exercise execution was carefully checked and participants were always verbally encouraged and motivated during all tests.

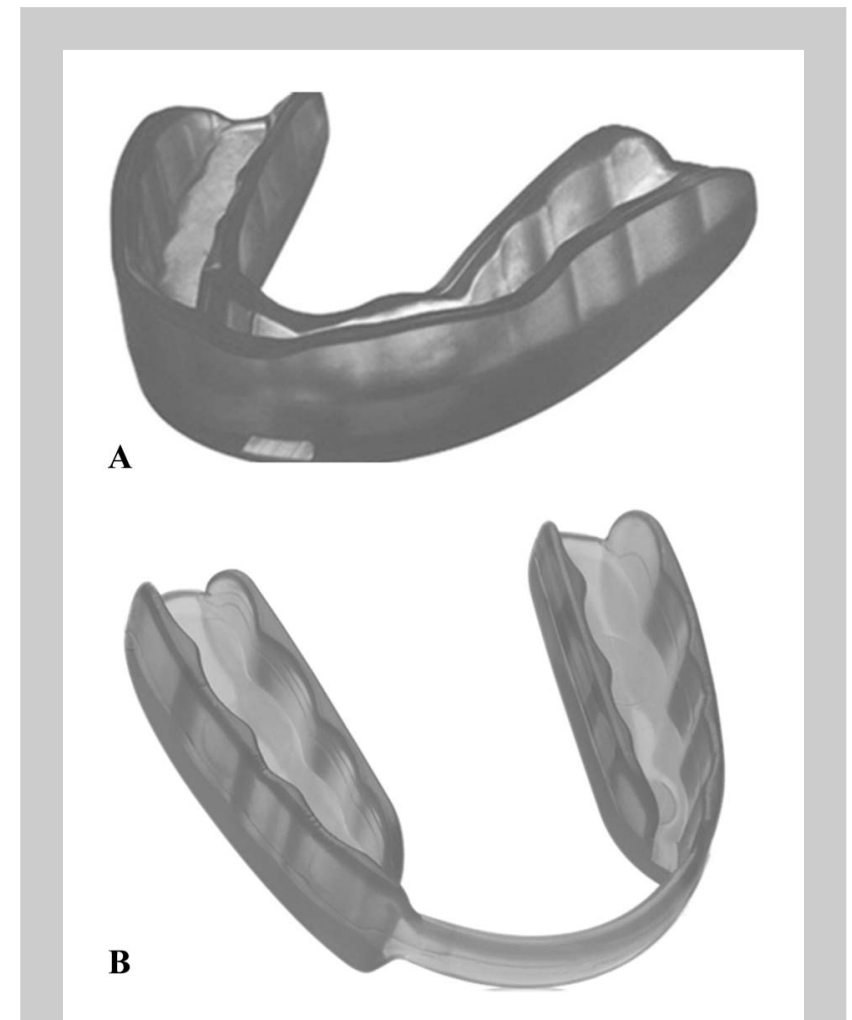

Figure 1. Pictures of the oral splints used during the tests: sport splint $\left(\mathrm{OS}_{\mathrm{SP}}\right.$, panel $\left.\mathrm{A}\right)$ equally distributed dental contacts and diurnal splint $\left(\mathrm{OS}_{\mathrm{D}}\right.$, panel $\left.\mathrm{B}\right)$, with only posterior dental contacts.

\section{Subjects}

Nine physically active men (age: $24 \pm 2$ years (22-26 years); stature: $1.78 \pm 0.10 \mathrm{~m}$; body mass: $69 \pm 10 \mathrm{~kg}$; training frequency: 2 per week; mean $\pm S D$ ) volunteered for this project. At the time of the study, none of them reported musculoskeletal pathologies of the upper limbs. Participants underwent a private dental visit at their family dental office to exclude the presence of TMJ disorders, acute inflammatory conditions, respiratory problems, and chronic pain from postural issues. Normal occlusal splint users were also excluded. Based on the outcomes, only the subjects exempt from the problems mentioned above were selected to participate in the study. After full explanation of the purpose of the study, the experimental procedures and benefits and risks of the investigation, signed informed consent was obtained from all participants included in the study, which was approved by the University of Milan's Ethics Committee, in accordance with the principles of the 1975 Declaration of Helsinki. Participants were naive about the experimental hypothesis.

\section{Procedures}

Each test was performed at approximately the same time of the day, in a climate-controlled laboratory (constant temperature of $20 \pm 1^{\circ} \mathrm{C}$ and relative humidity of $50 \pm$ $5 \%$ ). Participants were instructed not to eat for at least 
3 hours before tests. They were also asked to avoid ergogenic beverages for at least 8 hours before tests, and to abstain from heavy exercise of the upper limbs in the previous 48 hours. The splints used during the tests had different thickness and allowed for different occlusal contacts: the $\mathrm{OS}_{\mathrm{D}}$ was $1-\mathrm{mm}$ thick and had only posterior dental contacts, whereas the $\mathrm{OS}_{\mathrm{SP}}$ was 3 -mm thick and provided a neutral dental occlusion, with occlusal contacts equally distributed along the dental arch $(7,19)$. Participants dipped the splint into boiling water for 20 seconds and then inserted it in the mouth over the lower dental arch using the fingers and the tongue to shape it. If the splint location was unstable or inaccurate, the modeling procedure was repeated.

Maximum Voluntary Contraction. During MVC assessment, participants performed 3 maximum trials of the dominant side of elbow flexors each lasting 5 seconds, with 5 minutes of rest in between. The highest value was considered as the closest to the MVC, from which the $80 \%$ MVC was then calculated. During each contraction, force (F) and electromyographic (EMG) signals were recorded from the biceps brachii muscle for further analysis. F was recorded at a sampling rate of $128 \mathrm{~Hz}$ by a calibrated load cell (mod. SM-1000N; Scottsdale, AZ, USA) operating linearly between 0 and $1,000 \mathrm{~N}$, amplified (gain: $\times 200$ ) by a 16 bits A/D converter (mod. UM150; Biopac System, CA, USA). The surface EMG was acquired by a multichannel amplifier (mod. EMG-USB; OTBioelettronica, Turin, Italy; input impedance: $>90 \mathrm{M} \Omega$; CMRR: $>96 \mathrm{~dB}$; EMG bandwidth: $10-750 \mathrm{~Hz}$; gain: $\times 1,000)$ with a sampling rate of $2048 \mathrm{~Hz}$. Electromyography was detected in single differential modality by a linear array of 4 electrodes (mod. ELSCH004, OTBioelettronica, Turin, Italy; linear array $45 \times 20 \mathrm{~mm}$; electrode $2 \times 1 \mathrm{~mm}$; interelectrode distance $10 \mathrm{~mm}$ ) fixed to the skin by dual-adhesive foam (mod. AD004; OTBioelettronica) filled with conductive gel (Cogel, Comedical, Trento, Italy). The EMG array was oriented with the major axis parallel to the muscle fibers direction and with the EMG electrodes positioned perpendicularly to the major axes of muscle fibers. The skin area under the electrodes was cleaned carefully with ethyl alcohol and gently abraded with a special abrasive and conductive cream (Nuprep; Weaver and Co., Aurora, CO, USA) to achieve an interelectrode impedance below $2,000 \Omega$. To allow repeated measurements of the signals on different days from the same muscle area, a map with the EMG probe position, together with some landmarks (moles, angiomas and scars), was drawn on a transparency.

From the time and frequency domain analyses of the EMG signal, the root mean square (EMG RMS) and mean frequency (EMG MF) were calculated. From the EMG and $\mathrm{F}$ data, the neuromuscular efficiency (NE) was determined as the ratio [F/EMG RMS] at MVC that is how much electrical activity is required to produce a certain level of force output (22).

$100 \%_{60 s}$. Subjects were asked to reach as quickly as possible the $100 \% \mathrm{MVC}$ and to maintain that intensity for 60 seconds, trying to drop the force output as little as possible. During contraction, F and EMG signals were acquired and subsequently analyzed. From the $\mathrm{F}$ signal, the percentage of force decay $\left(\Delta_{\mathrm{Fi}-\mathrm{Fe}}\right)$ during $100 \%{ }_{60}$ s was determined. From the time and frequency domain analyses of the EMG signal, the EMG RMS and EMG MF were calculated.

$80 \%{ }_{e x h}$. Participants performed an isometric effort at $80 \%$ MVC to the point of fatigue, i.e., when they were no longer able to keep the force level constant within $\pm 5 \%$ of the target. This intensity was chosen because during this level of effort all motor units should be recruited and active (3). Also during this task, $\mathrm{F}$ and EMG signals were acquired and analyzed subsequently. From the $\mathrm{F}$ signal, the time of $\mathrm{F}$ within the target ( $\mathrm{t}$-target), the distance of $\mathrm{F}$ from the required target $(\Delta F)$, as an index of muscle contraction accuracy, and the coefficient of variation $(\mathrm{CoV})$ of $\mathrm{F}$ were calculated. Coefficient of variation was estimated as the ratio between the $\mathrm{SD}$ of the $\mathrm{F}$ in a considered time window and $\mathrm{F}$ average value in the same window $(\mathrm{CoV}=\mathrm{SD} /$ mean). This parameter can be considered as an index of muscle contraction stability (33). From the time domain analyses of the EMG signal, the EMG RMS was calculated.

In all testing protocols, participants were given specific instructions not to focus their attention on OS and teeth clenching while performing the requested isometric motor tasks to avoid any external influence on their usual teeth clenching behavior during physical efforts.

\section{Statistical Analyses}

Statistical analysis was performed using a statistical software package (SigmaPlot for Windows; v12, Systat Software Inc., San Josè, CA, USA). To check the normal distribution of the sampling, a Kolgomorov-Smirnov test was applied. A sample size of 9 participants was selected to ensure a statistical power higher than 0.80. A 1-way (condition) analysis of variance (ANOVA) was used for MVC, and a 2-way (condition $\times$ time) ANOVA for repeated measures was applied to determine possible differences in $\mathrm{F}$ and $\mathrm{EMG}$ variables during the different experimental conditions for $80 \%_{\text {exh }}$ and $100 \%$ 60s tests. The post hoc Holm-Sidak test was applied when necessary to establish the location of the differences. The level of significance was set at $\alpha<0.05$. A 2-way, mixed model intraclass correlation coefficient (ICC) was used to assess intersession reliability of MVC assessment between visit 2 and 3, 4, or 5. Intraclass correlation coefficient values were considered as very high if $>0.90$, high if between 0.70 and 0.89 , and moderate if between 0.50 and 0.69 . Unless otherwise stated, values are expressed as mean $\pm S E$. 


\section{Results}

\section{Maximum Voluntary Contraction}

Absolute MVC was significantly higher $(p=0.012)$ in $\mathrm{OS}_{\mathrm{SP}}$ $(378.5 \pm 39.9 \mathrm{~N} ; p \leq 0.05)$ and $\operatorname{OS}_{\mathrm{D}}(361.8 \pm 42.9 \mathrm{~N})$ than in control condition $(345.7 \pm 30.7 \mathrm{~N})$. Neuromuscular efficiency also showed higher $(p=0.048)$ values in $\mathrm{OS}_{\mathrm{D}}$ and $\operatorname{OS}_{\mathrm{SP}}(1,031.9 \pm 206.8 \mathrm{~N} / \mathrm{mV}$ and 1,222.4 $\pm 182.3 \mathrm{~N} / \mathrm{mV}$, respectively) with respect to $\operatorname{Ctrl}(822.4 \pm 109.3 \mathrm{~N} / \mathrm{mV}$, Figure 2, panel A and B). Both EMG RMS and EMG MF showed lower values $\left(\mathrm{OS}_{\mathrm{D}}: 0.37 \pm 0.08 \mathrm{mV}\right.$ and $131.9 \pm$ $4.2 \mathrm{~Hz}$ and $\mathrm{OS}_{\mathrm{SP}}: 0.34 \pm 0.09 \mathrm{mV}$ and $131.3 \pm 5.2 \mathrm{~Hz}$ for EMG RMS and EMG MF, respectively) than Ctrl (0.38 \pm $0.06 \mathrm{mV}$ and $147.6 \pm 6.6 \mathrm{~Hz}$ for EMG RMS and EMG MF, respectively). The difference reached statistical significance in $\mathrm{MF}(p=0.001)$ while indicated only a trend in RMS (Figure 2, panel C and D). Reliability for MVC measurements was between high and very high. Indeed, ICC values were $0.985,0.880$, and 0.915 under $\mathrm{Ctrl}, \mathrm{OS}_{\mathrm{D}}$, and $\mathrm{OS}_{\mathrm{SP}}$, respectively.

$\mathbf{8 0} \%_{\text {exh }}$

During $80 \%_{\text {exh }}$, t-target was $16.6 \pm 7.4$ seconds, $16.2 \pm 5.3$ seconds, and $15.4 \pm 4.4$ seconds in $\mathrm{OS}_{\mathrm{D}}, \mathrm{OS}_{\mathrm{SP}}$, and Ctrl, respectively. The differences were not significant.
For a more precise assessment of the differences among the 3 conditions in terms of electromechanical response, we decided to compare only the first 10 seconds of the isometric task, i.e., the maximum amount of contraction time that was reached by all participants at $80 \%$ MVC. Electromyographic RMS, $\Delta F$, and $\mathrm{CoV}$ values during $80 \% \mathrm{exh}_{\mathrm{exh}}$ are shown in Figure 3 . The initial values of EMG RMS were $0.374 \pm 0.081 \mathrm{mV} ; 0.406 \pm$ $0.024 \mathrm{mV}$; and $0.340 \pm 0.092 \mathrm{mV}$ for Ctrl, $\mathrm{OS}_{\mathrm{D}}$, and $\mathrm{OS}_{\mathrm{SP}}$, respectively. In the first 10 seconds, EMG RMS showed a progressive increase in all experimental conditions. $\Delta F$ starting values were $0.384 \pm 1.580 \%(\mathrm{Ctrl}),-0.647 \pm 1.972 \%\left(\mathrm{OS}_{\mathrm{D}}\right)$, and $-1.827 \pm 1.734 \%\left(\mathrm{OS}_{\mathrm{SP}}\right)$. The values during the first 10 seconds showed stability in the target force maintenance. Last, $\mathrm{CoV}$ started at $0.039 \pm 2.980(\mathrm{Ctrl}), 0.025 \pm 3.310\left(\mathrm{OS}_{\mathrm{D}}\right)$, and $0.033 \pm 4.950\left(\mathrm{OS}_{\mathrm{SP}}\right)$ and showed a decrease in the considered interval. As depicted in Figure 3, the 2-way ANOVA for repeated measures retrieved no differences for all variables among Ctrl, $\mathrm{OS}_{\mathrm{D}}$, and $\mathrm{OS}_{\mathrm{SP}}$. A time effect was observed in EMG RMS from the fifth second, in EMG MF from the sixth second, and in $\mathrm{CoV}$ immediately after the start of the test. There were no interactions between the 2 factors.

$100 \%_{60}$

The $\Delta_{\mathrm{Fi} \text {-Fe }}$ of maximal contraction was similar in Ctrl $(66.38 \pm 4.05 \%)$ and $\mathrm{OS}_{\mathrm{D}}(67.64 \pm 3.87 \%)$, but

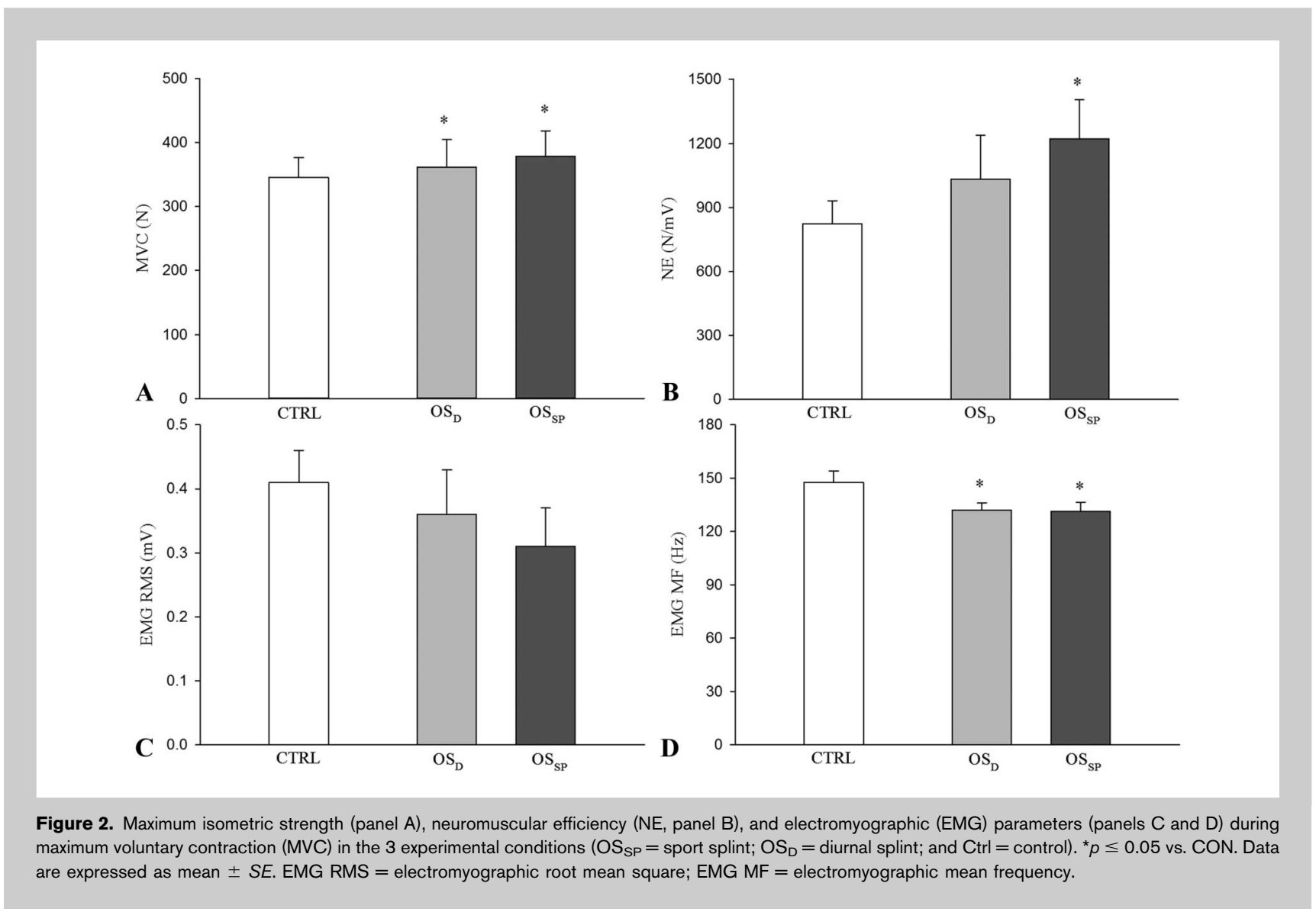




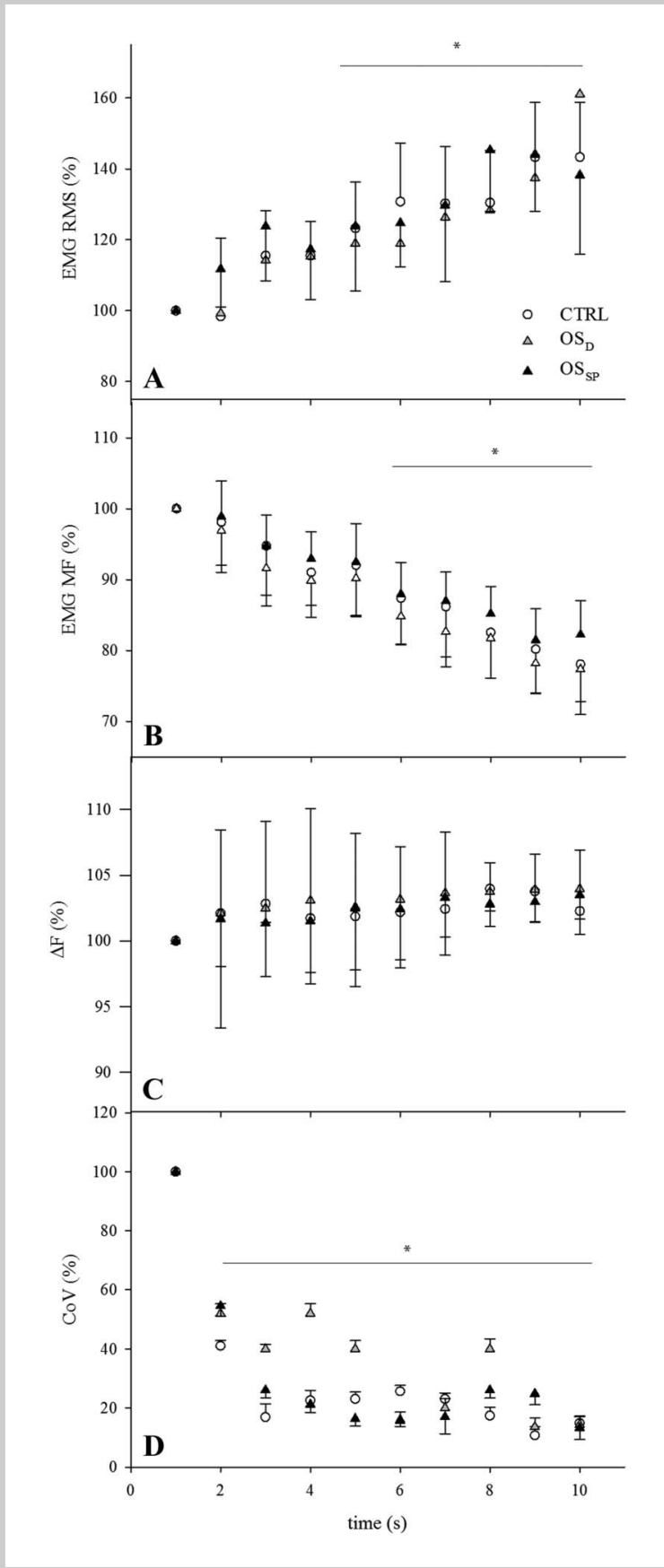

Figure 3. Electromyographic root mean square (EMG RMS, panel A) and mean frequency (EMG MF, panel B), distance of force output from the required target $(\Delta F$, panel $C)$, and coefficient of variation ( $\mathrm{CoV}$, panel $D)$ of $F$ during the first 10 seconds of $80 \%$ exh in the 3 experimental conditions $\left(\mathrm{OS}_{\mathrm{SP}}=\right.$ sport splint; $\mathrm{OS}_{\mathrm{D}}=$ diurnal splint; and $\mathrm{Ctrl}=$ control). Data are expressed as a percentage of the initial value $(=100 \%)$. ${ }^{*} p \leq 0.05$ vs. initial value. Data are expressed as mean $\pm S E$.

significantly lower in $\mathrm{OS}_{\mathrm{SP}}(60.88 \pm 5.46 \% ; p=0.013)$ (Figure 4, panel A).

$\mathrm{F}$ decreased progressively during the entire task. The initial values were $345.7 \pm 30.7 \mathrm{~N}, 361.8 \pm 42.9$

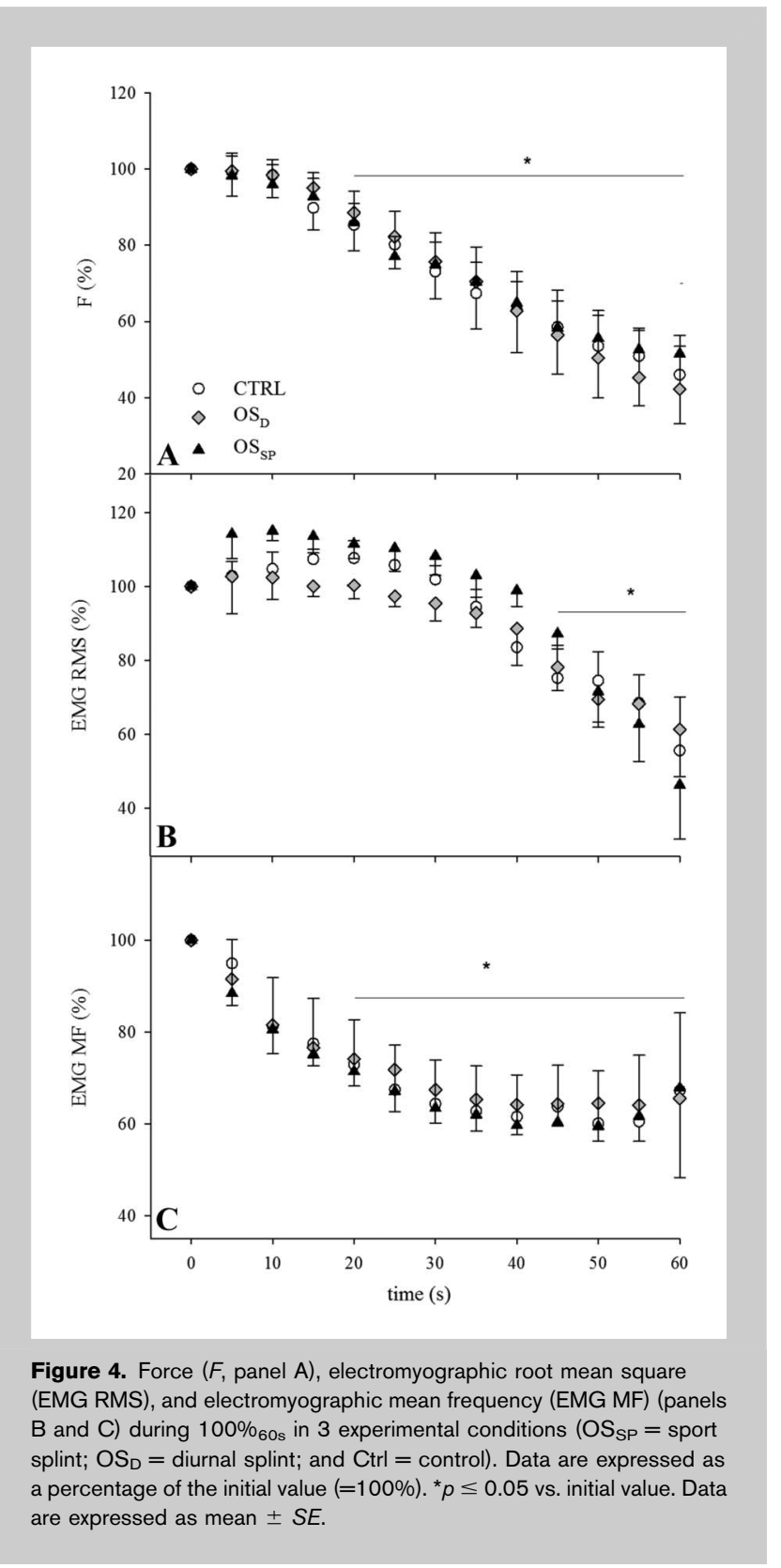

$\mathrm{N}$, and $378.5 \pm 39.9 \mathrm{~N}$ for $\mathrm{Ctrl}, \mathrm{OS}_{\mathrm{D}}$, and $\mathrm{OS}_{\mathrm{SP}}$, respectively.

Electromyographic RMS started with values of $0.38 \pm$ $0.06 \mathrm{mV}$ (Ctrl), $0.37 \pm 0.08 \mathrm{mV}\left(\mathrm{OS}_{\mathrm{D}}\right)$, and $0.34 \pm 0.09\left(\mathrm{OS}_{\mathrm{SP}}\right)$, then increased slightly in the first 30 seconds respect to initial values with a subsequent decline. Conversely, EMG MF started at $147.56 \pm 6.57 \mathrm{~Hz}(\mathrm{Ctrl}), 131.94 \pm 4.17 \mathrm{~Hz}\left(\mathrm{OS}_{\mathrm{D}}\right)$, and 120.74 $\pm 4.16 \mathrm{~Hz}\left(\mathrm{OS}_{\mathrm{SP}}\right)$, decreased during the first 30 seconds, then reaching a plateau (Figure 4, panel $\mathrm{B}$ and $\mathrm{C}$ ).

The 2-way ANOVA for repeated measures disclosed no differences in all variables among the 3 experimental conditions. A time effect was observed in $\Delta_{\mathrm{Fi}-\mathrm{Fe}}$ and EMG MF from the twentieth second, and in the last seconds of 
contraction in EMG RMS. There were no interactions between the 2 factors.

\section{Discussion}

The aim of this study was to assess the effects of 2 different kinds of occlusal splints (diurnal, $\mathrm{OS}_{\mathrm{D}}$ and sport splint, $\mathrm{OS}_{\mathrm{SP}}$ ) on the neuromuscular activation and isometric $\mathrm{F}$ output of the elbow flexor muscles. The response to fatiguing tasks was also evaluated. The main finding was that $\mathrm{OS}_{\mathrm{SP}}$ had a positive effect on maximum isometric strength capacity. During MVC, indeed, higher values were observed in $\mathrm{OS}_{\mathrm{SP}}$ than in Ctrl. Furthermore, a lower decline in $\mathrm{F}$ was observed with $\mathrm{OS}_{\mathrm{SP}}$ during a sustained MVC for 60 seconds. These results, together with EMG parameters, support the hypothesis of an improvement in NE of the elbow flexors (primary muscles) possibly induced by acute jaw repositioning through splint usage.

Unfortunately, at the time of the study, neither surface EMG activity nor force output of the masticatory muscles were recorded during the tests due to technical problems. Future studies implementing and quantifying neuromuscular activation and force output of masseter and temporalis anterior muscles during primary muscles contraction may provide further support to the interpretation of the present findings.

In the recent years, OS usage has raised questions about positive effects of this device not only on injury prevention but also on dynamic exercise performance. The possible mechanisms underlying this hypothesis involve potential postural readjustments and muscular rebalancing after chronic splint employment $(6,16)$. Indeed, jaw repositioning may correlate with postural control, functional proprioception, and spinal alignment. Changes in spinal alignment and proprioception may promote changes in physical movement and performance (16). The application of an OS may therefore result in a better redistribution of the clenching load, supporting the role that dental occlusion has on posture through the neuromuscular system (6).

However, whether acute splint usage affects maximum isometric strength and endurance has not been examined yet. In this study, we found higher MVC values in $\mathrm{OS}_{\mathrm{SP}}$ than in $\mathrm{OS}_{\mathrm{D}}$ and Ctrl. Together with the tendency toward a lower EMG RMS, this phenomenon implies a higher NE (ratio between $\mathrm{F}$ and EMG RMS) in $\mathrm{OS}_{\mathrm{SP}}$. These effects were detected acutely during isometric muscular tasks, given that regular splints users were excluded from the study. Therefore, postural adjustments that require long time to take place cannot be claimed to have had a role in these findings. Conversely, acute OS usage may have determined a distancing of the dental arches and a resulting elongation of the masticatory musculature that has been shown to induce beneficial ergogenic effects in healthy individuals (23), possibly by altering the proprioceptive feedback from the masticatory muscles. This feedback change in this study may have improved the muscle force generating capacity of the elbow flexors in terms of a better NE.
Moreover, some studies observed that the synchronous co-activation of more muscles (e.g., during handgrip) produces a maximum force expression lower than the sum of the maximum force capacity of the single muscles involved (e.g., single fingers) (11,35). A recent study (25) may provide additional evidence for the functional coupling of the craniomandibular system and muscular control, by observing an improvement in postural control through a reduced intervention of co-agonist secondary muscles with respect to the primary movement.

Overall, our and others' data may confirm the hypothesis that an amelioration of neuromuscular control of the primary muscles may have occurred during $\mathrm{OS}_{\mathrm{SP}}$ and $\mathrm{OS}_{\mathrm{D}}$ conditions, with a lower interference of ancillary feedback and, consequently, an improved contraction effectiveness. According to our data, mandibular stability through acute boil-and-bite splints usage may have induced a better stretching and realignment of masticatory muscles that led to higher MVC with a similar EMG activity, i.e., to a better $\mathrm{NE}$, which represents the muscle responsiveness to a neural excitation (8). Neuromuscular efficiency is based on the relationship between the force generated by a muscle and its EMG activity. Hence, the NE can be interpreted as the ability to produce higher levels of strength within a similar or lesser muscle activation (8).

A lower strength decline between the beginning and the end of the prolonged maximum contraction $\left(60 s_{\max }\right)$ was observed in $\mathrm{OS}_{\mathrm{SP}}$. Moreover, t-target during $80 \%_{\text {fatigue }}$ showed a tendency to be longer in both $\mathrm{OS}_{\mathrm{SP}}$ and in $\mathrm{OS}_{\mathrm{D}}$ compared with Ctrl. However, EMG parameters during both fatiguing tests showed no significant differences among the 3 investigated conditions. Overall, these findings seem to indicate an enhancement in NE, the previously described ratio between EMG activity and force output, rather than a modification of the motor unit recruitment strategy.

These responses were more evident in $\mathrm{OS}_{\mathrm{SP}}$ than in $\mathrm{OS}_{\mathrm{D}}$ possibly because of the different thickness and shape of the 2 splints (see Methods), allowing 2 very different kinds of occlusal contacts. Anterior dental contacts as in $\mathrm{OS}_{\mathrm{SP}}$, indeed, produce a higher TMJ load because of a longer lever arm. Moreover, the thicker $\mathrm{OS}_{\mathrm{SP}}$, by creating a greater distance between the 2 dental arches, may have induced a higher lengthening of the masticatory muscles and a possible consequent reduction of proprioceptive feedback from them.

In conclusion, acute splint usage had positive effects on maximum isometric strength and endurance. Force results, together with EMG parameters behavior, supported the hypothesis of an improvement in NE of the elbow flexors (primary muscles) possibly related to acute jaw repositioning. This response was more evident in ${ } S_{S P}$ than in ${ }_{O S}$ probably because of the different thickness of the 2 splints.

\section{Practical Applications}

Splint usage unveiled some positive effects on maximum isometric strength and endurance tasks. The concurrent 
tendency for a decreased central drive (lower EMG RMS during MVC) and the increase in maximum force output (higher MVC values) led to a significant improvement in $\mathrm{NE}$ when wearing $\mathrm{OS}_{\mathrm{SP}}$. Moreover, $\mathrm{OS}_{\mathrm{SP}}$ reduced force decay during prolonged maximum isometric contraction. Acute splint usage is therefore not only not detrimental for exercise performance but it may also improve it under certain circumstances, such as maximum isometric tasks.

\section{ACknowledgments}

The authors are in debt with all the people involved in this study, for their committed participation. The study was partly supported by Dr. BRUX Montefarmaco that provided the oral splints to be tested. The authors disclose no professional relationships with companies or manufacturers who will benefit from the results of this study. Results of this study do not constitute endorsement of the product by the authors or the NSCA.

\section{REFERENCES}

1. Allen, CR, Dabbs, NC, Zachary, CS, and Garner, JC. The acute effect of a commercial bite-aligning mouthpiece on strength and power in recreationally trained men. J Strength Cond Res 28: 499503, 2014

2. Alpini, DC, Di Berardino, F, Mattei, V, and Cesarani, A. The correlation between dental occlusion and posture is different in trained versus nontrained subjects. Sport Sci Health 7: 83-86, 2012.

3. Basmajian, JV and De Luca, CJ. Muscles Alive. Their Functions Revealed by Electromyography (5th ed.). Baltimore, MD: Williams and Wilkins Waverly Press, 1985.

4. Bemelmanns, $P$ and Pfeiffer, P. Shock absorption capacities of mouthguards in different types and thicknesses. Int J Sports Med 22: 149-153, 2001

5. Chakfa, AM, Mehta, NR, Forgione, AG, Al-Badawi, EA, Lobo, SL, and Zawawi, KH. The effect of stepwise increases in vertical dimension of occlusion on isometric strength of cervical flexors and deltoid muscles in nonsymptomatic females. Cranio 20: 264-273, 2002.

6. D’Ermes, V, Basile, M, Rampello, A, and Di Paolo, C. Influence of occlusal splint on competitive athletes performances. Ann Stomatol (Roma) 3: 113-118, 2012.

7. Dellavia, C, Sforza, C, Ghislanzoni, LTH, Rosati, R, and Ferrario, VF Types and uses of intraoral plaques. Dent Mod 29: 42-55, 2011.

8. Deschenes, MR, Giles, JA, McCoy, RW, Volek, JS, Gomez, AL, and Kraemer, WJ. Neural factors account for strength decrements observed after short-term muscle unloading. Am J Physiol Regul Integr Comp Physiol 282: R578-R583, 2002.

9. DeYoung, AK, Robinson, E, and Godwin, WC. Comparing comfort and wearability: Custom-made vs. self-adapted mouthguards. $J$ Am Dent Assoc 125: 1112-1118, 1994.

10. Drum, SN, Swisher, AM, Buchanan, CA, and Donath, L. Effects of a custom bite-aligning mouthguard on performance in college football players. J Strength Cond Res 30: 1409-1415, 2016.

11. Ebben, WP. A brief review of concurrent activation potentiation: Theoretical and practical constructs. J Strength Cond Res 20: 985991, 2006.

12. Francis, KT and Brasher, J. Physiological effects of wearing mouthguards. Br J Sports Med 25: 227-231, 1991.
13. Garabee, WF Jr. Craniomandibular orthopedics and athletic performance in the long distance runner: A three year study. Basal Facts 4: 77-81, 1981.

14. Gardiner, DM and Ranalli, DN. Attitudinal factors influencing mouthguard utilization. Dent Clin North Am 44: 53-65, 2000.

15. Goldstein, LB, McArdle, WD, Last, FC, Spina, R, Lichtman, S, Meyer, $\mathrm{JE}$, and Berger, AI. Temporomandibular joint repositioning and exercise performance: A double-blind study. Cranio 3: 385-391, 1985.

16. Golem, DL and Arent, SM. Effects of over-the-counter jawrepositioning mouth guards on dynamic balance, flexibility, agility, strength, and power in college-aged male athletes. J Strength Cond Res 29: 500-512, 2015.

17. Jung, JK, Chae, WS, and Lee, KB. Analysis of the characteristics of mouthguards that affect isokinetic muscular ability and anaerobic power. J Adv Prosthodont 5: 388-395, 2013.

18. Knapik, JJ, Marshall, SW, Lee, RB, Darakjy, SS, Jones, SB, Mitchener, TA, delaCruz, GG, and Jones, BH. Mouthguards in sport activities: History, physical properties and injury prevention effectiveness. Sports Med 37: 117-144, 2007.

19. Maurer, C, Stief, F, Jonas, A, Kovac, A, Groneberg, DA, Meurer, A and Ohlendorf, D. Influence of the lower jaw position on the running pattern. PLoS One 10: e0135712, 2015.

20. McHorris, WH. Occlusal adjustment via selective cutting of natural teeth. Part I. Int J Periodontics Restorative Dent 5: 8-25, 1985.

21. McHorris, WH. Occlusal adjustment via selective cutting of natural teeth. Part II. Int J Periodontics Restorative Dent 5: 8-29, 1985.

22. Milner-Brown, HS, Mellenthin, M, and Miller, RG. Quantifying human muscle strength, endurance and fatigue. Arch Phys Med Rehabil 67: 530-535, 1986.

23. Morales, J, Busca, B, Solana-Tramunt, M, and Miro, A. Acute effects of jaw clenching using a customized mouthguard on anaerobic ability and ventilatory flows. Hum Mov Sci 44: 270-276, 2015.

24. Padilla, R. Overcoming objections: Providing professionally made custom mouthguards. Dent Today 19: 84-86, 2000; 88-89.

25. Ringhof, S, Stein, T, Potthast, W, Schindler, HJ, and Hellmann, D. Force-controlled biting alters postural control in bipedal and unipedal stance. J Oral Rehabil 42: 173-184, 2015.

26. Roettger, M. Performance enhancement and oral appliances Compend Contin Educ Dent 30: 4-8, 2009.

27. Sane, J. Comparison of maxillofacial and dental injuries in four contact team sports: American football, bandy, basketball, and handball. Am J Sports Med 16: 647-651, 1988.

28. Smith, SD. Adjusting mouthguards kinesiologically in professional football players. N Y State Dent J 48: 298-301, 1982.

29. Solow, RA. Customized anterior guidance for occlusal devices: Classification and rationale. J Prosthet Dent 110: 259-263, 2013.

30. Stenger, JM, Lawson, EA, Wright, JM, and Ricketts, J. Mouthguards: Protection against Shock to head, Neck and teeth. J Am Dent Assoc 69: 273-281, 1964

31. Stokes, AN, Croft, GC, and Gee, D. Comparison of laboratory and intraorally formed mouth protectors. Endod Dent Traumatol 3: 255258, 1987.

32. Terebesi, S, Giannakopoulos, NN, Brustle, F, Hellmann, D, Turp, JC and Schindler, HJ. Small vertical changes in jaw relation affect motor unit recruitment in the masseter. J Oral Rehabil 43: 259-268, 2016.

33. Tracy, BL. Visuomotor contribution to force variability in the plantarflexor and dorsiflexor muscles. Hum Mov Sci 26: 796-807, 2007.

34. von Arx, T, Flury, R, Tschan, J, Buergin, W, and Geiser, T. Exercise capacity in athletes with mouthguards. Int J Sports Med 29: 435-438, 2008.

35. Zatsiorsky, VM, Li, ZM, and Latash, ML. Coordinated force production in multi-finger tasks: Finger interaction and neural network modeling. Biol Cybern 79: 139-150, 1998. 